\title{
ANÁLISE DA PURIFICAÇÃO DE BIODIESEL ETÍLICO DE ÓLEO DE CANOLA POR CENTRIFUGAÇÃO
}

\author{
J. F. MEDEIROS ${ }^{1}$, M. L. MENEZES ${ }^{1}$, L. F. dos SANTOS ${ }^{1}$, G. L. da IGREJA ${ }^{1}$, M. C. S. \\ GOMES $^{2}$, N. C. PEREIRA ${ }^{1}$, O. C. da MOTTA LIMA ${ }^{1}$ \\ ${ }^{1}$ Universidade Estadual de Maringá, Departamento de Engenharia Química. \\ ${ }^{2}$ Universidade Tecnológica Federal do Paraná, Tecnologia em Processos Químicos \\ E-mail para contato: janainafmedeiros1@hotmail.com
}

\begin{abstract}
RESUMO - Há um grande crescimento da produção de biodiesel no Brasil, que pode ser explicado pelas vantagens que o mesmo oferece e por isso, surge a necessidade de estudos para otimização do processo de produção. O objetivo deste trabalho é analisar a purificação do biodiesel por meio de centrifugação sem a retirada prévia do etanol. Para isso, o biodiesel foi produzido por transesterificação etílica de óleo de canola utilizando hidróxido de sódio como catalisador e purificado por centrifugação sem a pré-retirada do etanol. Porém, os resultados obtidos mostraram que não houve separação das fases, então foi adicionado ao biodiesel diferentes concentrações de água ou de água acidificada $(0,5$ e $1 \%$ ). O melhor resultado de centrifugação ficou na adição de $10 \%$ de água, com uma rotação de 2000 rpm e um tempo de 5 minutos, mostrando que este método é muito eficaz para a purificação do biodiesel.
\end{abstract}

\section{INTRODUÇÃO}

A produção de biodiesel no Brasil está em grande crescimento e esse crescimento pode ser explicado pelas vantagens que o biodiesel oferece. Segundo a Agência Nacional do Petróleo, Gás natural e Biocombustíveis - ANP, os biocombustíveis poluem menos por emitirem menos compostos no processo de combustão dos motores, além da tendência do processo de produção ser mais limpo.

De acordo com Parente (2003), biodiesel é um combustível renovável, biodegradável e ambientalmente correto, sucedâneo do óleo diesel mineral. É constituído de uma mistura de ésteres metílicos ou etílicos de ácidos graxos, obtidos da reação de transesterificação de qualquer triglicerídeo com um álcool de cadeia curta, como o metanol ou etanol.

Sob o ponto de vista técnico e econômico, a reação via metanol é muito mais vantajosa que a reação via etanol. Segundo Steluti (2007), no Brasil é uma vantagem utilizar etanol, pois a oferta desse álcool é grande em todo o território nacional, além de ser derivado de biomassa, tornando o biodiesel um produto verdadeiramente renovável. Porém, há uma dificuldade na separação das fases que se formam após a reação de transesterificação. Uma alternativa seria o uso do processo de centrifugação, já que o mesmo acelera o processo de decantação. 


\section{9 a 22 de outubro de 2014 \\ Florianópolis/SC}

Steluti (2007) avaliou a separação das fases de uma "mistura sintética" constituída de biodiesel, glicerina e etanol, por meio do processo de centrifugação. Neste estudo, foram avaliadas amostras com diferentes concentrações de etanol e avaliado o tempo de decantação da fase glicerina de diferentes amostras e constatado que a presença do etanol, realmente, aumenta a solubilidade do biodiesel na glicerina e vice-versa, agindo como um cossolvente e, dessa forma, dificultando o processo de separação dessas substâncias por decantação. Nos ensaios de centrifugação, variou-se o tempo de residência (2, 3 e 4 minutos), velocidade de rotação (1000, 2000 e $3000 \mathrm{rpm})$, temperatura $\left(25,30\right.$ e $\left.55^{\circ} \mathrm{C}\right)$ e quantidade de etanol $(3,6$ e 9 mols $)$ presente no meio, chegando nas melhores condições de operação da centrífuga: $1000 \mathrm{rpm}$, tempo de residência de 4 minutos e $25^{\circ} \mathrm{C}$ ou 3000 rpm, tempo de residência de 2 minutos e $25^{\circ} \mathrm{C}$.

Santos et al. (2009), realizaram a purificação de biodiesel, de óleo de soja, adicionando-se $10 \mathrm{~mL}$ de glicerina para alterar o sistema ternário (biodiesel:etanol:glicerina) e acelerar a formação nítida de duas fases. Estas foram formadas após a lavagem com solução saturada de $\mathrm{NaCl}$ que removeu o excesso de etanol e a glicerina residual.

Gomes et al. (2013), estudaram o uso de adição de água acidificada na purificação de biodiesel por microfiltração e seus resultados mostraram um grande efeito na remoção de glicerol da fase de biodiesel. Esta remoção ocorre porque a adição de água promove a formação de uma fase aquosa, incluindo glicerina, sabão e etanol, formando aglomerados com tamanho médio maior do que o diâmetro dos poros da membrana.

A adição de água pode melhorar a separação de fases biodiesel/glicerol, pois segundo Saleh et al. (2010), a adição de uma concentração mássica de água ao biodiesel maior do que 0,06\% proporciona um aumento considerável dos aglomerados de glicerol. Os resultados obtidos pelos autores demonstraram que o tamanho dos aglomerados aumentou de $0,25 \mu \mathrm{m}$ na concentração de $0,06 \%$ para 3,0 $\mu \mathrm{m}$ com a adição de $0,2 \%$ de água.

A utilização de água acidificada também tem uma tendência em melhorar a separação das fases biodiesel/glicerol, pois segundo Knothe et al. (2006), o ácido neutraliza o catalisador residual e quebra qualquer quantidade de sabão que tenha se formado durante a reação. Sabões reagirão com o ácido, formando sais solúveis em água e ácidos graxos livres.

Uma forma de se verificar a eficiência da purificação é pela análise do teor de glicerol contido no biodiesel purificado. A ANP define uma quantidade máxima de $0,02 \%$ em massa de glicerol no biodiesel.

Deste modo, o objetivo deste trabalho é analisar a purificação do biodiesel por meio de centrifugação, mostrando a viabilidade deste processo com relação ao processo convencional de purificação de biodiesel, que consiste em lavagens com água acidificada aquecida e posterior decantação. 


\section{MATERIAIS E MÉTODOS}

O óleo de canola bruto utilizado nos experimentos foi fornecido pela Cooperativa Agroindustrial Cocamar (Maringá, Paraná). O etanol anidro foi fornecido pela Usina Santa Terezinha (Tapejara, Paraná). O catalisador utilizado foi hidróxido de sódio de grau analítico, na forma de micropérolas, adquirido da Biotec.

A caracterização do óleo de canola bruto foi realizada por meio das análises de densidade (densímetro digital da marca Anton Paar, modelo DMA 5000), viscosidade (reômetro digital da marca Brookfield modelo DV-III), umidade (Karl Fischer da marca Analyser, modelo Umidade Controle KF-1000), acidez e saponificação (método do Instituto Adolfo Lutz (2008)).

O biodiesel foi produzido pela reação de transesterificação, conduzida em balão de três bocas equipado com um agitador mecânico e um termômetro, imerso em um banho térmico. Foram utilizadas as condições do planejamento experimental de Gomes et al., (2012) com os dados de razão molar, temperatura, tempo de agitação e rotação que proporcionaram os maiores rendimentos em ésteres etílicos. Para cada reação, foram colocadas $1000 \mathrm{~g}$ de óleo no balão, que permaneceu sob agitação até que se atingisse a temperatura desejada de $30^{\circ} \mathrm{C}$. Foram previamente misturados $10 \mathrm{~g}$ de hidróxido de sódio e $390 \mathrm{~g}$ do etanol até completa dissolução do catalisador e adicionados ao balão, onde a mistura permaneceu sob agitação em torno de 350 rpm, por uma hora.

Para a centrifugação utilizou-se um planejamento DCCR (Delineamento Composto Central Rotacional) com 2 variáveis (tempo e rotação) e 4 repetições no ponto central. A rotação variou de 1000 a $7000 \mathrm{rpm}$ e o tempo de 1 a 30 minutos.

Buscando eliminar a etapa previa de retirada do etanol, o processo de purificação foi realizado por centrifugação, por meio das seguintes propostas:

1) Centrifugação do biodiesel sem a pré-retirada do etanol.

2) Centrifugação do biodiesel sem a pré-retirada do etanol com tratamento prévio: adição de água nas concentrações de 5 e $10 \%$.

3) Centrifugação do biodiesel sem a pré-retirada do etanol com tratamento prévio com solução aquosa de ácido clorídrico, nas concentrações de 5 e $10 \%$.

A avaliação da eficiência da centrifugação na separação das fases (biodiesel e glicerol) foi feita por meio da análise do teor de glicerol livre, realizada pelo método titulométrico (metodologia modificada, baseada no método oficial da AOCS (Ca 14-56)).

\section{RESULTADOS E DISCUSSÃO}

A Tabela 1 apresenta os resultados da caracterização do óleo de canola bruto. 
Tabela 1 - Resultados da caracterização do óleo

\begin{tabular}{lc}
\hline Acidez $(\%)$ & 2,39 \\
Umidade $(\%)$ & 0,17 \\
Densidade $\left(\mathrm{kg} / \mathrm{m}^{3}\right)$ & 916,48 \\
Viscosidade a $40^{\circ} \mathrm{C}\left(\mathrm{mm}^{2} / \mathrm{s}\right)$ & 33,97 \\
Índice de Saponificação & 188,88 \\
\hline
\end{tabular}

A partir dos resultados da Tabela 1, é possível analisar as condições do óleo. Observa-se uma acidez considerada elevada para a transesterificação alcalina, porém, em razão da existência de trabalhos apresentando bons resultados para esta reação com o uso de óleo de canola bruto com 2,40\% de acidez (Gomes et al., 2013) e a possibilidade de redução dos custos de tratamento da matéria-prima, não foi realizado pré-tratamento no óleo.

$\mathrm{Na}$ primeira etapa, o processo de centrifugação sem tratamento prévio não promoveu a separação das fases glicerol e biodiesel em nenhuma das condições operacionais estudadas (rotação e tempo). Isso pode ser explicado pelo fato do etanol ser um cossolvente (dissolve tanto polar quanto apolar), fazendo com que o glicerol fique dissolvido no biodiesel. Steluti (2007) estudando a purificação de biodiesel por centrifugação de amostras "sintéticas" de uma mistura de biodiesel, glicerol e etanol, encontrou resultados diferentes. Como no trabalho atual estuda-se a amostra "real" da produção de biodiesel e não a sintética, isso pode ser explicado devido à presença de outros componentes nesta amostra "real", não estarem deixando a separação de fases ocorrer.

Nas próximas etapas, foram adicionadas às misturas resultantes da reação, diferentes proporções de água. A Figura 1 apresenta os resultados do teor de glicerol contido no biodiesel após as centrifugações com adição de 5 e $10 \%$ de água ao biodiesel. A Figura 2 apresenta a superfície de resposta para a adição de $10 \%$ de água ao biodiesel de canola.

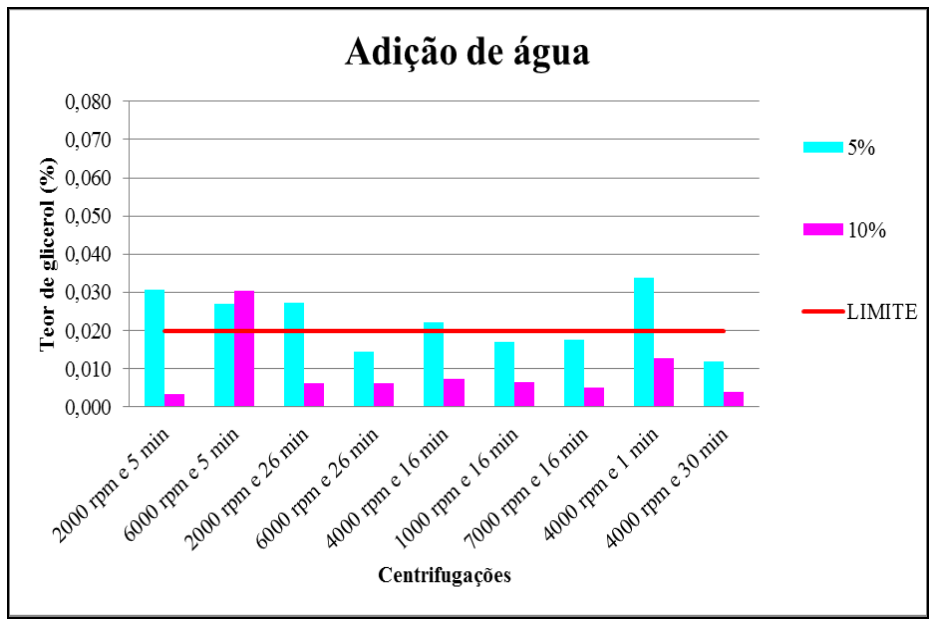

Figura 1 - Resultados da centrifugação do biodiesel com adição de água.

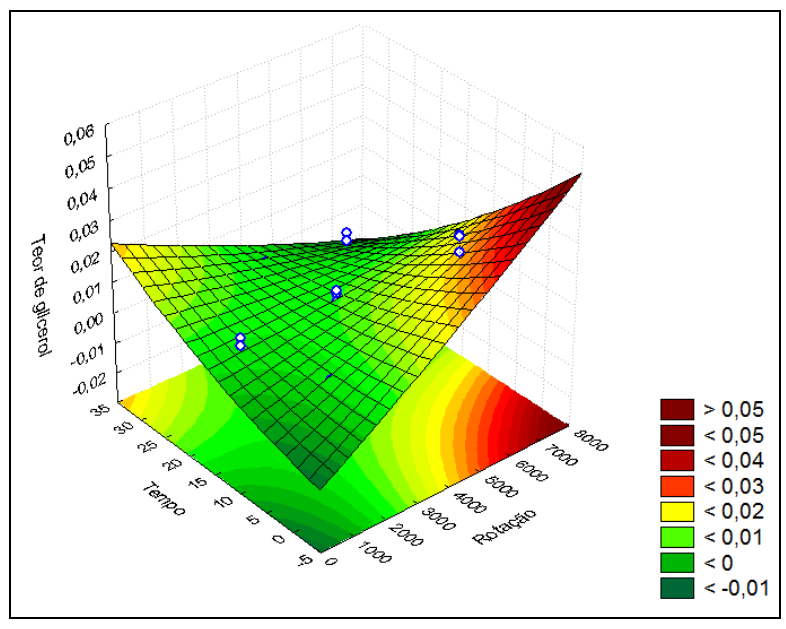

Figura 2 - Superfície de resposta com adição de $10 \%$ de água. 
Pela Figura 1, pode-se perceber que a adição de 5\% de água ao biodiesel proporcionou valores de teor de glicerol dentro da especificação da ANP para as centrifugações com $6000 \mathrm{rpm}$ por 26 minutos, $1000 \mathrm{rpm}$ por 16 minutos, $7000 \mathrm{rpm}$ por 16 minutos e $4000 \mathrm{rpm}$ por 30 minutos. Na adição de $10 \%$, pode-se verificar um melhor resultado para quase todas as centrifugações. Somente a centrifugação a $6000 \mathrm{rpm}$ por 5 minutos apresentou um teor de glicerol maior do que o permitido pela ANP. Um bom resultado é a centrifugação a $2000 \mathrm{rpm}$ por 5 minutos que se torna viável pela rotação e tempo baixos.

Na Figura 2, pode-se observar uma ampla utilização de rotação e tempo de centrifugação, sendo necessário evitar somente rotações altas com tempos muito baixos. Verifica-se que o tempo deve aumentar proporcionalmente com a rotação para se obter bons resultados.

A separação das fases biodiesel e glicerol ocorre em função da adição de água proporciona a formação de uma fase dispersa aquosa, contendo glicerol, catalisador, sais e outras substâncias solúveis em água, distinta da fase rica em ésteres etílicos e óleo não reagido. Ou seja, a presença de água diminui a solubilidade dos ésteres no glicerol, proporcionando a coalescência do glicerol em gotículas maiores, e, assim, a sua decantação é mais rápida (Saleh et al., 2010).

Na Figura 3, são apresentados os resultados para a centrifugação do biodiesel com adição de 5 e $10 \%$ de água acidificada $(0,5 \% \mathrm{v} / \mathrm{v}$ de $\mathrm{HCl})$ ao biodiesel. $\mathrm{Na}$ Figura 4, encontra-se a superfície de resposta com adição de $10 \%$ de água acidificada $(0,5 \% \mathrm{v} / \mathrm{v}$ de $\mathrm{HCl})$ ao biodiesel variando com a rotação e tempo de residência da centrifugação.



Figura 3 - Resultados da centrifugação do biodiesel com adição de água acidificada a $0,5 \%$.

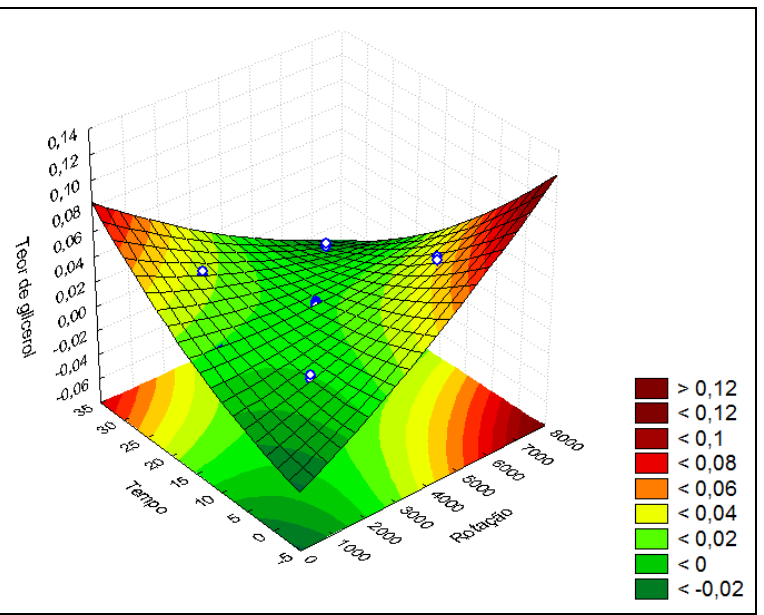

Figura 4 - Superfície de resposta com adição de $10 \%$ de água acidificada a $0,5 \%$.

Pela Figura 3, pode-se verificar que a adição de 5\% apresentou resultados do teor de glicerol dentro da especificação para as centrifugações com $2000 \mathrm{rpm}$ por 26 minutos, $6000 \mathrm{rpm}$ por 
26 minutos e $4000 \mathrm{rpm}$ por 30 minutos. $\mathrm{Na}$ adição de $10 \%$, pode-se verificar um melhor resultado para quase todas as centrifugações. Somente as centrifugações a $6000 \mathrm{rpm}$ por 5 minutos e $2000 \mathrm{rpm}$ por 26 minutos apresentaram um teor de glicerol maior do que o permitido pela ANP. Um bom resultado é a centrifugação a 2000 rpm por 5 minutos que se torna viável pela rotação e tempo baixos.

Por meio da Figura 4, pode-se perceber uma ampla utilização de rotação e tempo de centrifugação, sendo necessário evitar rotação alta com tempo muito baixo e rotação baixa com tempo alto, isso explica a significância da interação entre os termos.

Na Figura 5, é apresentado os resultados do teor de glicerol contido no biodiesel após as centrifugações com adição de 5 e $10 \%$ de água acidificada (1\% v/v de $\mathrm{HCl})$ ao biodiesel. Na Figura 6 , encontra-se a superfície de resposta dos experimentos com adição de $10 \%$ de água acidificada (1\% v/v de $\mathrm{HCl}$ ) ao biodiesel variando com a rotação e tempo de residência da centrifugação.



Figura 5 - Resultados da centrifugação do biodiesel com adição de água acidificada a $1 \%$.

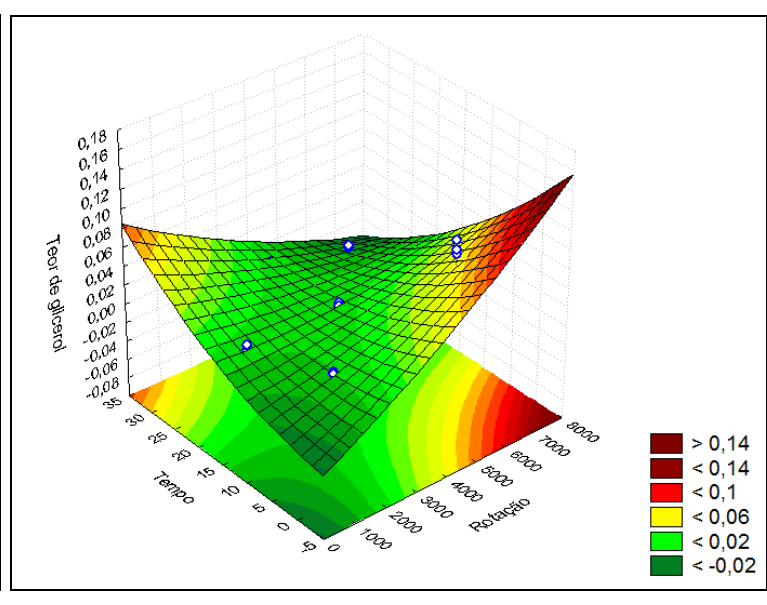

Figura 6 - Superfície de resposta com adição de $10 \%$ de água acidificada a $1 \%$.

Pela Figura 5, pode-se verificar que a adição de 5\% apresentou resultados do teor de glicerol dentro da especificação para as centrifugações com $6000 \mathrm{rpm}$ por 5 minutos e $4000 \mathrm{rpm}$ por 30 minutos. Na adição de $10 \%$ pode-se verificar um melhor resultado para quase todas as centrifugações. Somente a centrifugação a $6000 \mathrm{rpm}$ por 5 minutos apresentou um teor de glicerol maior do que o permitido pela ANP. Um bom resultado é a centrifugação a $2000 \mathrm{rpm}$ por 5 minutos, que se torna viável pela rotação e tempo baixos.

Pela Figura 6, percebe-se uma ampla faixa de rotação e tempo de centrifugação pode ser utilizada, sendo necessário evitar rotação alta com tempo muito baixo e rotação baixa com tempo alto, isso explica a interação entre os termos ser significativa. 
Das análises com água acidificada a melhor opção é a utilização de $0,5 \%$, pois apresenta bons resultados do teor de glicerol e utiliza a menor quantidade de ácido $(\mathrm{HCl})$, viabilizando assim o processo de purificação.

Considerando o processo de produção e purificação do biodiesel, temos que, do ponto de vista econômico e ambiental, a proporção de $10 \%$ de água, rotação de $2000 \mathrm{rpm}$ e tempo de 5 minutos são as melhores condições encontradas.

Percebe-se que, para concentrações baixas, são necessários tempos maiores de centrifugação. Assim sendo, é necessário realizar uma análise de custo a fim de verificar o que seria mais viável: o uso de uma concentração maior, com tempos e rotações menores (2000 rpm e 5 minutos) ou concentrações menores, com rotações e tempos maiores (6000 rpm e 26 minutos).

\section{CONCLUSÃO}

Nas condições em que os ensaios foram conduzidos, concluiu-se que, para a adição de 5\% de água ao biodiesel, a centrifugação a $1000 \mathrm{rpm}$ por 16 minutos mostrou-se muito eficaz para a purificação. Para a adição de 10\% de água ao biodiesel, a centrifugação com 2000 rpm por 5 minutos também apresentou um bom resultado para o teor de glicerol, sendo viável por utilizar um tempo menor de centrifugação.

Para a adição de água acidificada a $0,5 \%$ v/v de $\mathrm{HCl}$ na concentração de 5\%, o melhor resultado está na centrifugação com $2000 \mathrm{rpm}$ por 26 minutos. Para a adição de 10\%, obteve-se resultados satisfatórios para a centrifugação com 2000 rpm e 5 minutos, que se torna viável pela rotação e tempo menores.

Percebe-se que, para baixas concentrações, são necessários tempos maiores de centrifugação. Assim sendo, é necessário realizar uma análise de custo a fim de verificar o que seria mais viável.

Analisando todos os resultados, a melhor escolha seria a adição de água ao biodiesel, pois é a alternativa mais acessível e econômica que fornece resultados satisfatórios.

A centrifugação do biodiesel sem a pré-retirada do etanol, não promove a separação de fases, sendo necessário a adição de água ou água acidificada para que a purificação por centrifugação ocorra de forma eficiente.

O processo de centrifugação para purificação de biodiesel em substituição ao processo convencional mostrou-se eficaz pela diminuição do tempo do processo, redução da quantidade de efluente gerado e economia de energia para a retirada do etanol e no aquecimento da água de lavagem. 


\section{REFERÊNCIAS}

ANP, 2013. Agência Nacional do Petróleo, Gás Natural e Biocombustíveis.

ANVISA, Agência Nacional de Vigilância Sanitária. RDC No 482, de 23 de setembro de 1999. Caracterização de óleos vegetais.

GOMES, M. C. S. Estudo da produção de biodiesel por transesterificação etílica e sua purificação utilizando processos com membranas. Maringá: UEM, 2012. Tese (Doutorado em Engenharia Química) - Universidade Estadual de Maringá, 2012.

GOMES, M. C. S.; ARROYO, P. A.; PEREIRA, N. C. Influence of acidified water addition on the biodiesel and glycerol separation through membrane technology. Journal of Membrane Science. v. 431 , p. $28-36,2013$.

INSTITUTO ADOLFO LUTZ, Métodos físico-químicos para análise de alimentos. Coordenadores Odair Zenebon, Neus Sadocco Pascuet e Paulo Tiglea, $4^{\text {a }}$ edição, São Paulo: Instituto Adolfo Lutz, 2008.

KNOTHE, G.; VAN GERPEN, J.; KRAHL, J.; RAMOS, L. P. Manual de biodiesel, Ed. Edgard Blucher, São Paulo, 2006, 340p.

PARENTE, E. J. S. Biodiesel: uma aventura tecnológica num país engraçado. Fortaleza: Unigráfica, 2003. 66p.

SALEH, J.; TREMBLAY, A.Y.; DUBÉ, M.A. Glycerol removal from biodiesel using membrane separation technology. Fuel, v. 89, p. 2260-2266, 2010.

SANTOS, A.P.B.; PINTO, A.C. Biodiesel: Uma Alternativa de Combustível Limpo. Química Nova na Escola, v. 31, p. 58 - 62, 2009.

STELUTI, A. J. C. Estudo do Processo de Separação das Fases Biodiesel-Glicerina por Centrifugação. Maringá: Universidade Estadual de Maringá, 2007. 50 p. Dissertação (Mestrado em Engenharia Química). 